\title{
Study on efficacy of probiotic in broiler chickens diet
} \author{
Farhad Mirzaei $^{1^{*}}$, Alireza Alinejad ${ }^{3}$ \\ ${ }^{1}$ Animal Science Research Institute, Karaj, Iran; ${ }^{*}$ Corresponding Author: farmir2005@gmail.com \\ ${ }^{2}$ College of Agriculture, University of Tehran, Karaj, Iran \\ ${ }^{3}$ College of Agriculture, Islamic Azad University, Ghaemshahr, Iran
}

Seyed Mozafar Seyed Mehdizadeh Taklimi ${ }^{1}$, Hushang Lotfollahian $^{1}$, Ahmad Zarea Shahne $^{2}$,

Received 20 September 2011; revised 25 November 2011; accepted 19 December 2011

\begin{abstract}
400 days old chicks were distributed randomly into 4 treatments and 4 replicates in each treatment ( 25 birds in each replicate) and fed standard feed. The effects of different levels of probiotic in diets for $\mathbf{4 9}$ days were studied. Humoral immune responses were studied by conducting experiments on cellular proliferation, entry and survival of beneficial bacteria in gut, immunoglobulin titers. Mean body weight. Gain, feed intake and feed efficiency were recorded significantly $(P<0.05)$. Immune response of chicks through study of levels of anti-body productions (even after SRBC injections) in experimental groups were also significantly different as compared with the control group $(P<0.01)$. The bacteriological and intestinal morphology studies were showed significantly different in birds, when fed probiotics. Therefore, it can be suggested the probiotic (Biomin Imbo) can be safely used at the rate of $0.1 \%, 0.05 \%$ and $0.025 \%$ in starter, grower and finisher diets. The aim of the experiment was to evaluate whether selected probiotic (Biomin Imbo) $3 \times 10^{8} \mathrm{cfu} / \mathrm{g}$ have different immunomodulating effects in broiler chickens.
\end{abstract}

Keywords: Broiler; Immunology; Intestinal Morphology; Probiotic

\section{INTRODUCTION}

Since decades, with the advent and development of synthetic and semi-synthetic antibiotics and hormones which have been used as animal feed additives. However, increasing concerns regarding over use of antibiotics has prompted extensive investigation into alternatives. Hence, research workers have been experienced throughout the last five decades and being directed to the research back to natural antimicrobial products as indispensable re- sources. Consequently there is considerable research interest in the possible use of natural products, like, vitamin supplements, enzymes, probiotics, medicinal plants and herbs for the development of new additives in animal feeding. Incorporation of natural feed additives as growth promoters in some countries is not exceeding more than 10 to 20 years. Use of probiotics, as animal feed additives, in our region is still new and need more emphasize to develop its applications.

Probiotics are live microorganisms which will have beneficial effect to the host animal by improving its intestinal microbial balance through inhibiting intestinal pathogens (E. coli). In fact mode of actions of probiotic is still unclear despite the suggestions given [1],1) beneficial changes in gut flora with reductions in the population of Escherichia coli, 2) lactate production with subsequent changes in intestinal $\mathrm{pH}, 3$ ) production of antibiotic-type substances, 4) production of enzymes, 5) competition for adhesion receptors in the intestine, 6) competition for nutrients, 7) reduction of toxin release and immuno-stimulation.

There were contradictory results concerning by the use of probiotic in the feeds, whether the growth performance of poultry would be affected and improved or not. This was reported that, inclusions of lactobacillus in layer hen diets, improved plackets tissues in illume, though, it was acting as stimulating agents for the immune system to produce antigens [2].

[3] showed that, the supplementation of probiotics along with injections of sheep red blood cells, revealed higher levels of anti-body productions in broiler chicks. In the other studies when the broiler diet was enriched with probiotic, they also observed the increasing trend of lactic acid and reductions of $\mathrm{pH}$, which was initiating steps to inhibit the establishment of $E$. coli and Salmonella bacteria in the gut. It was reported that, probiotics had significantly effects on feed efficiency and did not affect the weight gain and feed intake significantly, but increased levels of lactic acid productions in the gut [4]. This was showed that, probiotic (Biomin Imbo) enhanced micro flora compositions in the gut and reduced 
mortality [5]. It was also reported that, blood anti-body titration against bronchitis was increased while; broiler chicks were fed probiotics [6].

\section{MATERIALS AND METHOD}

\subsection{Experimental Design and Husbandry}

The experiment was conducted under completely randomized design by procuring four hundred day old unsexed cobb chicks which were allotted randomly into four treatment and four replicate in each treatment (25 chick in each replicate). The probiotic (Biomin Imbo $3 \times$ $10^{8} \mathrm{cfu} / \mathrm{g}$ ) was procured and used in this experiment. The birds were offered standard feed ad lib for 49 days. The four experimental diets described as follows:

1) Basal diet (not supplemented probiotic Biomin Imbo), 2) Basal diet $+0.05 \%, 0.1 \%$ and $0.15 \%$ for starter, 3) Basal diet $+0.025 \%, 0.05 \%$ and $0.075 \%$ for grower, and 4) Basal diet $+0.125 \%, 0.025 \%$ and $0.0375 \%$ for finishing diets were offered for ad lib for 49 days. Different parameters such as performance, immune response, bacteriology, morphology of digestive tract and Production Index were studied. Meanwhile, during experimental period, two birds were selected randomly from each replicate and sacrificed to study the above different parameters.

\subsection{Performance}

In this case, weekly body weight gain, daily feed intake, feed efficiency, carcass percentage and production index were studied at the end of experimental period.

\subsection{Immunology Response}

The selected birds (at age of 21 days) were injected $0.1 \mathrm{ml}$ of $0.5 \%$ Sheep red blood cells (SRBC) in the wings. $2 \mathrm{ml}$ of blood were collected after $7^{\text {th }}$ and $14^{\text {th }}$ days of post injection. Then anti-body titrations of samples were evaluated.

\subsection{Bacteriological Assay}

Bacterial populations were studied through the sam- ples which were collected from the Illume. The samples were analyzed for the bacterial colonies like, coli form, lactobacillus, clostridiums, bifido bacterium and staphylococcus facium.

\subsection{Intestinal Morphology}

Morphology of illume was studied through the measurement of the width, length and depth of villie and crypt cells respectively.

\subsection{Statistics}

The collected data were statistically analysed by using the soft wear of SAS and means were compared under Duncan models.

\section{RESULTS AND DISCUSSION}

Probiotic effects may be due to a great efficiency in the utilization of feed, resulting in improvement of the growth. It is known that, probiotics have digestion stimulating properties and anti microbial establishing ability due to multiplications of beneficial microorganisms in the gut.

\subsection{Performance}

As result shows in Table 1, Probiotic supplementation had increased mean daily body weight gain significantly throughout the experimental period $(\mathrm{P}<0.05)$. The highest mean body wt gain was observed in treatment 4 as compared with treatments 2 and $1(\mathrm{P}<0.05)$. The highest and the lowest feed intake were observed in treatments 1 and 4, $(\mathrm{P}<0.05)$. Feed intake was low, when the levels of probiotic reduced in the diet at the finishing stage. Mean feed efficiency was affected by inclusions of high level of probiotic. Therefore, better feed efficiency at the trail period was referred to treatment $4(\mathrm{P}<0.05)$. This finding was in accordance to the previous research work [7]. Production index (PI) is a very important criterion as point of view to the producers. As results revealed probiotic had significantly effect on production index in treatment 4 , $(\mathrm{P}<0.05)$. Carcass and

Table 1. Effect of probiotic on performance of broiler (0 - 49 days).

\begin{tabular}{cccc}
\hline Parameters/Treatments & 1 (Control) & 2 & 3 \\
Mean Body Wt. Gain (gr./hen/day) & $34.04 \pm 1.70^{\mathrm{c}}$ & $36.94 \pm 1.62^{\mathrm{b}}$ & $41.70 \pm 1.02^{\mathrm{a}}$ \\
Mean Feed Intake (gr./hen/day) & $77.71 \pm 1.97^{\mathrm{a}}$ & $75.84 \pm 0.99^{\mathrm{a}}$ & $72.33 \pm 1.26^{\mathrm{b}}$ \\
Mean Feed Efficiency & $2.28 \pm 0.12^{\mathrm{a}}$ & $2.05 \pm 0.11^{\mathrm{b}}$ & $1.73 \pm 0.06^{\mathrm{c}}$ \\
Mean Carcass (\%) & $60.06 \mathrm{~ns}$ & 60.98 & 61.39 \\
Production Index & $164.00^{\mathrm{c}}$ & $223.00^{\mathrm{b}}$ & 62.50 \\
\hline
\end{tabular}

Values in the rows with different superscripts are significantly different $(\mathrm{P}<0.05)$. 
body wt. are having positive correlations, since supplementation of probiotic improved carcass percentage. The higher mean live body wt. was observed in treatment 4, subsequently which were considered better carcass percentage and remain non-significant [8].

\subsection{Immunology Response}

The results of Table 2, indicated, probiotic had significant effects on anti-body productions against common diseases (Bronchitis, Newcastle, Influenza) except IBD as compared to the control groups ( $\mathrm{P}<0.05)$. Treatment 4 had higher anti-body productions against Newcastle disease $(\mathrm{P}<0.05)$ whereas, treatment 3 was shown to have higher anti-body production against both in bronchitis and influenza significantly $(\mathrm{P}<0.05)$. Nevertheless, the other experimental groups were recorded lower levels of anti-body productions against both diseases $(\mathrm{P}<0.05)$.It was evidenced that probiotic had positive effects and improved the immune system by producing high level of blood anti body via increasing the health status of the birds. The results of one week post SRBC injections, as shown in Table 2, treatment 1 had the lowest anti-body titrations and performed was the least $(\mathrm{P}<0.05)$. At the two week post SRBC injections, treatment 4 and 3 had the highest anti-body titrations respectively as compared to the other groups $(\mathrm{P}<0.05)$. This results, were in accordance with the published reports [6]. It was known that, presence of beneficial micro flora in the gut would have considerable effect on the immune systems by compatibly neglecting the pathogens in the gut, which enhanced the disease resistance of the birds. Even though, vicinal immunity was almost certainly immunologic in nature and in combinations with probiotic will have excellent situations for developing beneficial micro flora to multiply its number faster to eliminate combatively pathogens in the gut.

\subsection{Bacteriological Assay}

As results were revealed, in Table 3, the highest and the lowest mean Coli form bacteria concentrations were belong to treatment 1 and 2 respectively $(\mathrm{P}<0.01)$. In view of mean lactobacillus bacteria concentrations, treatment 4 had the highest levels as treatment 3 had the lowest rate and differences among them were significant ( $\mathrm{P}<0.01)$. The presence of highest levels of bifidobacterium concentrations were related to treatment 3 and 4 (P $<0.05)$. Though the highest levels of staphylococcus faecium were owed to treatment 1 as compare to other experimental groups $(\mathrm{P}<0.01)$.These results were in accordance to the [9]. Hence, it is believed that, probiotics supplementations had significantly acted important role to establish the beneficial micro flora in the gut. While, it has been considering the gut will be very sensitive to the types of food and production environments.

\subsection{Intestinal Morphology}

As result shows in Table 4, treatment 3 and 4 had significantly different in width and length size of villie as compare to other experimental groups $(\mathrm{P}<0.01)$. Treatment 4 had the highest depth of crypt cells as compare to other groups $(\mathrm{P}<0.01)$. In view of the size of width of crypt cells, significant differences were observed between treatment 3,2 and 4 respectively $(\mathrm{P}<0.01)$. It shows probiotic indulged to improve width, length and depth of crypt cells, which will improve the rate of digestibility and absorptions of nutrient that ingested by the birds. There is evidence, which proved by increased length of villie, it will create an increasing trend of actions of intestinal absorptions [10]. The elongated villie, will inhibit the fast passage of food, reduced moistening of food particles and finally will improve feed efficiency. Whenever, more number of pathogens is present in the

Table 2. Effect of probiotic on immune response (anti body prod.) of broiler (0 - 49 days).

\begin{tabular}{|c|c|c|c|c|c|}
\hline Description/Treatment & 1 & 2 & 3 & 4 & $\mathrm{MSE} / \mathrm{CV}$ \\
\hline Newcastle & $1.144^{\mathrm{c}}$ & $1.147^{\mathrm{C}}$ & $1.222^{\mathrm{b}}$ & $1.274^{\mathrm{a}}$ & $0.47 / 6.07$ \\
\hline Bronchitis & $1.166^{\mathrm{ab}}$ & $1.046^{\mathrm{b}}$ & $1.266^{\mathrm{a}}$ & 1.174 & $0.55 / 11.12^{\mathrm{ab}}$ \\
\hline Infectious B.D. (IBD) & 1.166 & 1.127 & 1.138 & 1.266 & $0.45 / 4.97$ \\
\hline Influenza & $1.313^{\mathrm{b}}$ & $1.322^{b}$ & $1.346^{\mathrm{a}}$ & $1.316^{\mathrm{b}}$ & $0.49 / 7.11$ \\
\hline \multicolumn{3}{|c|}{ Anti body Productions } & \multicolumn{3}{|c|}{ Treatments } \\
\hline Post SRBC Injection/ & 1 & 2 & 3 & 4 & $\mathrm{MSE} / \mathrm{CV}$ \\
\hline $7^{\text {th }}$ day & $2.75^{\mathrm{a}}$ & $3.38^{\mathrm{ab}}$ & $3.7^{\mathrm{b}}$ & 3. $88^{\mathrm{b}}$ & $0.365 / 17.50$ \\
\hline $14^{\text {th }}$ day & $2.13^{\mathrm{a}}$ & $2.38^{\mathrm{a}}$ & $2.50^{\mathrm{ab}}$ & $2.88^{\mathrm{b}}$ & $0.089 / 12.10$ \\
\hline
\end{tabular}

Values in the rows with different superscripts are significantly different $(\mathrm{P}<0.05)$. 
Table 3. Effect of Probiotic on bacteriological assay of broiler (0 - 49 days).

\begin{tabular}{ccccc}
\hline Micro flora/Treatment & 1 & 2 & 3 & MSE/CV \\
Coli form & $18.50^{\mathrm{a}}$ & $17.06^{\mathrm{b}}$ & $15.54^{\mathrm{c}}$ & $16.52^{\mathrm{b}}$ \\
Lactobacillus & $16.59^{\mathrm{b}}$ & $18.07^{\mathrm{a}}$ & $15.36^{\mathrm{b}}$ & $1.33 / 3.4$ \\
Bifid bacterium & $15.98^{\mathrm{ab}}$ & $15.45^{\mathrm{b}}$ & $16.92^{\mathrm{a}}$ & $1.61 / 7.4$ \\
Staph. fascism & $17.87^{\mathrm{a}}$ & $16.90^{\mathrm{b}}$ & $16.88^{\mathrm{b}}$ & $1.35 / 7.09$ \\
\hline
\end{tabular}

Values in the rows with different superscripts are significantly different $(\mathrm{P}<0.01)$.

Table 4. Effect of probiotic on morphology of illeume of broiler ( $\mu \mathrm{g})$ (0 - 49 days).

\begin{tabular}{|c|c|c|c|c|c|}
\hline Description/treatment & 1 & 2 & 3 & 4 & MSE/ CV \\
\hline Width of Ville & $7.13^{\mathrm{c}}$ & $17.08^{b}$ & $19.55^{\mathrm{a}}$ & 20.40 & $1.20 / 0.84$ \\
\hline Length & $51.25^{\mathrm{c}}$ & $58.78^{\mathrm{b}}$ & $63.69^{\mathrm{a}}$ & $64.85^{\mathrm{a}}$ & $2.36 / 2.57$ \\
\hline Depth of Crypt Cells & $23.06^{\mathrm{d}}$ & $28.75^{\mathrm{b}}$ & $27.04^{\mathrm{c}}$ & $31.91^{\mathrm{a}}$ & $1.91 / 4.99$ \\
\hline
\end{tabular}

Values in the rows with different superscripts are significantly different $(\mathrm{P}<0.01)$.

gut, the number of beneficial bacteria will be reduced.

\section{REFERENCES}

[1] Montes, A.J. and Pugh, D.G. (1993) The use of probiotics in food-animal practice. Veterinary Medicine, 88, 282288.

[2] Nahashon, S.N., Nakaue, H.S. and Mirosh, I.W. (1996) Performance of single comb white leghorn fed a diet supplemented with a live microbial during the growth and egg laying phases. Animal feed Science Technology, 57, 25-38. doi:10.1016/0377-8401(95)00852-7

[3] Panda, A.K., Reddy, M.R., Ramarao, S.V. and Praharaj, N.K. (2000) Effect of dietary supplementation of probiotic on performance and immune response of layers in decline phase of production. Indian Journal of Poultry Science, 3, 102-104.

[4] Samanta, M. and Biswas, P. (1995) Effect of feeding probiotic and lactic acid on the performance of broiler. Journal of Indian Poultry Science, 30, 145-147.

[5] Mohnl, M. (2006). Benefits from using biomin c-x and biomin imbo in poultry production. Biomin Newsletter, 4 , 37.
[6] Roughani, E., Arab, M. and Akbarian, A. (2007) Effects of probiotic and other feed additives on performance and immune response of broiler chicks. Department of Animal Science, Shiraz University, Shiraz, Iran.

[7] Midilli, M., Alp, M. and Turan, N. (2008) Effect of dietary Probiotic and prebiotic supplementation on growth, performance and serum IgG concentration of broilers. South African Journal of Animal Science, 38, 21-27. doi:10.4314/sajas.v38i1.4104

[8] Shoeib, H.K. and Madian, A.H. (2000) A study on the effect of breeding diets containing probiotics (pronifer and biogen) on growth performance, intestinal flora and hematological picture of broiler chicks. Assiut Veterinary Medicine Journal, 47, 112-125.

[9] Awood, M.H.H. (2003) Probiotics, perbiotics and immune-stimulation: More than an alternation for antibiotic growth promoters. Biomin Newsletter, 1, 4.

[10] Ahmad, L. (2004) Effect of probiotic (protexin) on the growth of broilers with special reference to the small intestinal crypt cells proliferation. Phill M Thesis, Biotechnology Center, Pishawar University, Pakistan. 